\title{
REVISED Tourette syndrome research highlights from 2019
}

\section{[version 2; peer review: 2 approved]}

\author{
Andreas Hartmann (D1), Yulia Worbe1, Kevin J. Black (DD2
}

${ }^{1}$ Department of Neurology, APHP, Paris, Île-de-France, 75013, France

2Department of Psychiatry, Neurology, and Radiology,, Washington University School of Medicine, Saint Louis, MO, 63110, USA

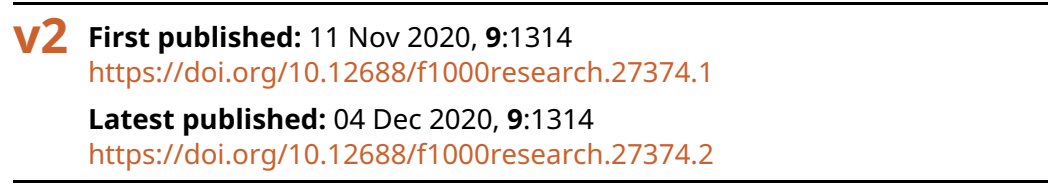

Abstract

This is the sixth yearly article in the Tourette Syndrome Research Highlights series, summarizing research from 2019 relevant to Tourette syndrome and other tic disorders. The highlights from 2020 is being drafted on the Authorea online authoring platform; readers are encouraged to add references or give feedback on our selections comments feature on this page. After the calendar year ends, this article is submitted as the annual update for the Tics collection F1000Research.

Keywords

Tics, Tourette syndrome, 2019

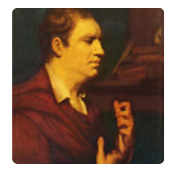

This article is included in the Tics collection.

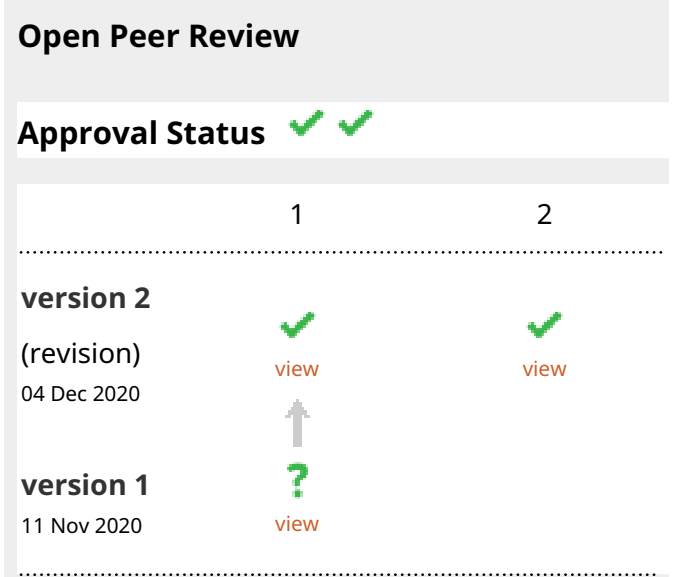

1. Natalia Szejko (D), Medical University of Warsaw, Warsaw, Poland

Yale University, New Haven, USA

2. Tammy Hedderly (iD), Evelina Children's Hospital, London, UK

GSTT/KCL, London, UK

Any reports and responses or comments on the article can be found at the end of the article. 
Corresponding author: Andreas Hartmann (andreas.hartmann@aphp.fr)

Author roles: Hartmann A: Conceptualization, Writing - Original Draft Preparation, Writing - Review \& Editing; Worbe Y:

Conceptualization, Writing - Original Draft Preparation, Writing - Review \& Editing; Black KJ: Conceptualization, Writing - Original Draft Preparation, Writing - Review \& Editing

Competing interests: KJB participated in a clinical trial supported by Emalex Biosciences. AH has received consultation fees from Lundbeck and Noema Pharma.

Grant information: This work was supported in part by the U.S. National Institutes of Health (NIH), grant R01 MH104030. The funders had no role in study design, data collection and analysis, decision to publish, or preparation of the manuscript.

Copyright: @ 2020 Hartmann A et al. This is an open access article distributed under the terms of the Creative Commons Attribution License, which permits unrestricted use, distribution, and reproduction in any medium, provided the original work is properly cited.

How to cite this article: Hartmann A, Worbe $Y$ and Black KJ. Tourette syndrome research highlights from 2019 [version 2; peer review: 2 approved] F1000Research 2020, 9:1314 https://doi.org/10.12688/f1000research.27374.2

First published: 11 Nov 2020, 9:1314 https://doi.org/10.12688/f1000research.27374.1 


\section{REVISED Amendments from Version 1}

We thank the reviewer for their appreciation of our work. As requested, we have expanded on the paper regarding TBI and TS. References 1 and 17 were reformatted so as to begin with the author's name.

Any further responses from the reviewers can be found at the end of the article

\section{Introduction}

This article is meant to disseminate recent scientific progress on Gilles de la Tourette Syndrome (TS).

\section{Methods}

We searched PubMed from time to time during 2019 using the search strategy "("Tic Disorders"[MeSH] OR Tourette NOT Tourette[AU]) AND 2019[PDAT] NOT 1950:2018[PDAT]". Colleagues also recommended articles, and we attended selected medical conferences. We selected material for this review subjectively, guided by our judgment of possible future impact on the field.

\section{Results}

\section{Phenomenology and natural history}

Müller-Vahl et al. ${ }^{1}$ present a stimulating argument based on data that demonstrate a severity continuum between chronic tics and TS using a database regrouping 1018 subjects. They thus conclude that TS and chronic tics do not represent distinct diagnostic categories. Accordingly, they suggest the introduction of the the term "tic spectrum disorders" (in analogy to autism spectrum disorders, ASDs) which might present the added benefit of decreased social stigma related to TS.

Martino and Hedderly provide an excellent review on the differences between tics and stereotypies, and their clinical management ${ }^{2}$

A useful resource is the video atlas of various vocalizations that includes tics and helps with differential diagnosis ${ }^{3}$.

Epidemiology. Several good epidemiological studies and meta-analyses on the childhood prevalence of TS have been published over the past years, with most figures ranging between 0.5 to $0.8 \%$, but they could be much higher. However, prevalence in adulthood remains unknown. Levine et al. analysed three studies (published 1986, 2011 and 2016) involving 2,356,485 participants ${ }^{4}$. Overall prevalence of TS in adulthood was estimated to be 118 cases of TS per million adults, that is $0.0118 \%$. This appears very low, even factoring in remission in two thirds to three quarters of childhood cases during adulthood (which, in itself, is debatable). Clearly, more research is needed on this important topic, preferably using current DSM-5 criteria.

Tic suppression. Forty-five children with tics starting on average only 3-4 months ago were assessed with clinical and psychological methods and reassessed at the 12-month anniversary of their first tic ${ }^{5}$. Children who were less able at the first visit to suppress tics while given immediate rewards for 10-second tic-free intervals had worse clinical status (higher YGTSS total tic score) at the follow-up visit six to nine months later. This finding adds to the meager prognostic clues available for Provisional Tic Disorder a simple, clinically relevant test.

Sensory phenomena and premonitory urges. Rae and colleagues provide a very thoroughly discussed computational model of how tics and premonitory sensations may be generated ${ }^{6}$. The model links premonitory phenomena and tics to a hypothesized overly precise internal estimate of sensory information and predicted movement, and has the key advantage of generating some testable hypotheses.

Other. David Mataix-Cols' group continue their epidemiological exploration of patients with TS and chronic tic disorders (CTD) using the Swedish National Patient Register. This time, they looked for metabolic and cardiovascular disorders in these patients and find that the risk is doubled compared to the general population, especially with regard to obesity, type 2 diabetes and circulatory system diseases. With regard to co-morbidities, the presence of attention-deficit/ hyperactivity disorder (ADHD) significantly increased the risk (however, excluding ADHD does not normalize the risk, still $50 \%$ higher than in the general population). Most surprisingly, use of antipsychotic medication for more than one year was associated with a significantly decreased risk for metabolic and cardiovascular disorders in patients with TS or CTD. This counterintuitive finding, given antipsychotics' propensity to induce metabolic syndrome, requires further clarification. For now, the authors speculate that patients with TS or CTD receiving medication benefit from frequent follow ups and better monitoring of their general health. In any case, this is a further demonstration, after papers on suicide and educational attainment in patients with TS or CTD, that chronic tic disorders are far from benign and require correct diagnosis, then regular care and follow up?

\section{Etiology}

Genetics. 2019 has seen the publication of a variety of studies using whole exome sequencing. Depienne et al. ${ }^{8}$ investigated 120 TS patients and identified disrupting variants of OPRK1, encoding the opioid kappa receptor, in a significant subset of subjects compared to controls. This result points to a role, discussed since the 1980s, of the opioid system as involved in the pathophysiology of TS and also suggest a new potential therapeutic target.

After whole exome sequencing of 100 trios (TS patients and their parents), point mutations in ASH1 Like Histone Lysine Methyltransferase (ASH1L) causing defects in its enzymatic activity were identified as a susceptibility gene for $\mathrm{TS}^{9}$, previously associated with mental retardation and autism. A transgenic mouse line (Ashll heterozygous mice) indeed displayed tic-like motor and compulsive behaviors, and dopaminergic hyperinnervation was observed in the dorsal striatum, demonstrating good construct validity for this model. 
Two more genes, chromodomain helicase DNA binding protein 8 (CHD8) and Signal Peptide, CUB Domain And EGF Like Domain Containing 1 (SCUBE1), were identified by whole exome sequencing in a cohort of 222 OCD parent-child trios, and it was further shown that these genes overlap with genes previously implicated in $\mathrm{TS}^{10}$. Of note, Katayama et al. (2016) demonstrated that mice heterozygous for Chd8 mutations manifest ASD-like behavioral characteristics including increased anxiety, repetitive behavior, and altered social behavior ${ }^{11}$.

Using the Swedish National Registry, it was shown that maternal polycystic ovary syndrome (PCOS), as a model for investigating the role of prenatal androgen exposure, is a risk for TS, ADHD and $\mathrm{ASD}^{12}$. These results support a potential causal influence of prenatal androgen exposure on the development of male-predominant neuropsychiatric disorders in female offspring of women with PCOS.

Still in Sweden, Brander et al. ${ }^{13}$ investigated whether, at the population level, tic-related OCD has a stronger familial load than non-tic-related OCD. They found that the risk of OCD in relatives of individuals with tic-related OCD was considerably greater than the risk of OCD in relatives of individuals with non-tic-related OCD, concluding that tic-related OCD is a particularly familial subtype of OCD. The results have important implications for ongoing gene-searching efforts.

Environmental risk factors. The EMTICS study was a large European multicenter trial investigating, among several subjects, the role of immunology in the etiology of tics, a long-discussed hypothesis in the context of Pediatric Acute-onset Neuropsychiatric Syndrome (PANS) / Pediatric Autoimmune Neuropsychiatric Disorders Associated with Streptococcal Infections (PANDAS). A first paper on neuronal surface proteins on 188 patients with TS failed to confirm a link between pathogenic antibodies and causation of tics ${ }^{14}$. In line with these findings, Baumgaertel et al. ${ }^{15}$ failed to detect autoantibodies in the CSF of 20 adult patients with TS. However, $20 \%$ of these patients had positive oligoclonal bands, an intriguing finding with no clear-cut explanation to date. Also, in the neuroimmunological field, Gilbert provides a thoughtful review of the PANDAS/PANS controversy ${ }^{16}$.

Chen et al. ${ }^{17}$, using the National Health Insurance Research Database of Taiwan, analyzed 2261 TS patients and 20349 non-TS controls for the risk of traumatic brain injury (TBI). During follow-up, there was a significantly increased risk for TBI in TS patients compared to controls. Classic comorbidities such as ADHD, OCD and depression increased the risk for TBI, whereas the regular use of antipsychotic medication decreased it. These findings have important therapeutic implications, as it underlines the need to offer proper and sustained anti-tic treatment in patients, even if these treatments may be sedative, as may be the case for antipsychotics.

\section{Pathophysiology}

Singer and Augustine have published two excellent and exhaustive reviews on the pathophysiology of tics/TS (including controversies) and the relevance for pharmacotherapy ${ }^{18,19}$.
Electrophysiology. Loo et al. ${ }^{20}$ performed a 128-channel electroencephalogram (EEG) study on children with TS during an exaggerated blink task and showed overall higher gamma band spectral power and differences in theta, alpha, and beta band power in inferior parietal cortex in TS children compared to controls.

Niccolai et al. ${ }^{21}$ studied motor-related beta oscillations in TS using magnetoencephalography and showed a biphasic increasedecrease pattern of beta oscillations. The decrease of beta oscillations was observed close to tic execution, similarly to what was observed in voluntary actions. The initial increase in beta power positively correlated with premonitory urges. Similarly, Zaparolli et al. ${ }^{22}$ studied the neural activity over the sensorimotor cortex using EEG during a finger movement task in TS and found decreased levels of beta modulation compared to controls in tic-free conditions. However, the abnormal pattern normalized if the patients were actively suppressing tics during the task.

Zhu et al. ${ }^{23}$ recorded local field potentials in the globus pallidus internus (GPi) and sub-thalamic nucleus (STN) of patients with TS and found that beta and gamma oscillations in the GPi were restored after deep brain stimulation (DBS) of the GPi but not after DBS of the STN, suggesting that these oscillations may play a role in pathophysiology of persistent tics. Another study using microelectrode recordings of the STN during DBS surgery in a single TS patient was able to identify a single unit activity of the STN within the delta band, which was reliably associated to optimal DBS target site for tic control ${ }^{24}$.

Neuroimaging studies. Ramkiran et al. ${ }^{25}$ used graph theoretical measures applied to resting-state functional magnetic resonance imaging (fMRI) in adults with TS and studied functional properties of different portions of cortico-basal ganglia-cerebellar networks. They showed increased basal ganglia-cortical and thalamo-cortical connectivity but reduced cortico-cerebellar connectivity compared to controls. The authors also reported reductions in serial information transfer within the default mode and the salience functional networks. Altogether, the findings suggested disruption of interoceptive mechanisms and of brain maturation, as well as a shift towards excitatory neurotransmission in TS.

Sigurdson et $a .^{26}$ focussed on cerebellar morphology and structural connectivity (structural co-variance) in TS and found reduced grey matter volumes in part of the cerebellum involved in motor and cognitive information processing compared top controls. The cerebellum also had abnormal structural connectivity with sensori-motor networks and fontal and cingulate cortices. These findings highlight the importance of the cerebellum in tic pathophysiology. The same approach of structural co-variance was used to study the structural underpinnings of premonitory urges with a specific focus on the right insula ${ }^{27}$. The severity of tics and premonitory urges correlated, respectively, with posterior (representing the current physiological state) and anterior (associated with urges for action) sub-regions of the insula. In addition, these sub-regions of insular cortex were related to different structural networks, suggesting that separate networks support tics and premonitory urges in TS. 
In one of the largest to date studies on resting state functional connectivity in adults and children with TS, Neilson et al. ${ }^{28}$ showed that patterns of functional connections alterations were age-dependent: while brain networks in TS children presented features of older age, adult TS brain networks appeared "younger" in comparison to age-matched controls. Overall, these findings underline the differences in TS neurodevelopmental trajectories.

Finally, O'Neil et al. wrote a comprehensive review about neuroimaging findings on the role of the cingulate cortex in TS, suggesting that at least six to eight different sub-regions of this cortical area might be implicated in different aspects of TS pathophysiology, and are especially involved with premonitory urges $^{29}$. Activity in the subgenual and pregenual anterior cingulate as well as in the middle cingulate cortex might represent volitional effort, physical discomfort and emotional distress of premonitory urges; the posterior middle cingulate cortex and dorsal posterior cingulate cortex might play a role in amplification (build-up) of urges.

A positron emission tomography study of 33 adults found that serotonin transporter (SERT) binding in caudate and midbrain was normal in people with tics only or OCD only, but was elevated in people with both tics and $\mathrm{OCD}^{30}$. This result, if replicated, may suggest a nosological distinction between TS with vs. without OCD, which would be surprising from a clinical viewpoint.

Clinical and neuropsychological studies. Recent studies indicate that the coordination of bimanual movements may involve a number of brain areas: primary sensorimotor cortex, supplementary motor area (SMA), premotor cortex, cingulate motor cortex, lateral premotor cortex, basal ganglia, inferior parietal cortex, and the cerebellum (many of which, incidentally, have been reported to be altered with respect to structure and/or function in brain imaging studies of TS). However, it is accepted that interhemispheric transfer is mediated through excitatory and inhibitory transcallosal communications between cortical motor areas and that the corpus callosum therefore plays a major role in the coordination of bimanual movements, particularly asymmetric bimanual movements. A recent study investigated externally paced (cued) and internally paced bimanual tapping in adults with and without TS. Importantly, this study combined behavioral measures of bimanual tapping with MRI-based diffusion tensor imaging and probabilistic tractography of inter-hemispheric callosal connections between the SMA and the left SMA-putamen fiber $\operatorname{tract}^{31}$. TS patients were significantly less accurate than healthy individuals when asked to maintain a previously copied rhythmic tapping speed at time intervals $<1 \mathrm{~Hz}^{32}$. Unimanual tapping is the condition requiring the greatest level of interhemispheric inhibition. TS patients also showed altered fractional anisotropy in interhemispheric (SMA-SMA) and left-sided SMA-putamen fiber tracts. These findings are consistent with compensatory processes linked to self-regulation of motor control that may occur through the plastic rearrangement of interhemispheric and cortical-subcortical WM pathways.
Maigaard and colleagues studied the ability of children with TS to suppress quick but inappropriate rewards ${ }^{33}$. Not surprisingly, children with ADHD did poorly on this task, but children with TS actually did better than healthy control children. All groups improved their accuracy when a reward was promised for accuracy. One hypothesis to explain these results may be that children with TS have better motor inhibition in certain tasks due to their experience withholding tics in response to premonitory urges due to social pressures. The reward effect may correspond to the known improvement in tic suppression in the presence of immediate rewards ${ }^{5,34}$.

\section{Treatment}

Psychological interventions. In a large study of manualized CBT in children with OCD, anxious and depressive symptoms improved substantially and were not linked to improvements in OCD severity ${ }^{35}$. This result is one more argument in favor of psychotherapy for obsessions and compulsions, which are common in people with tics. A consensus report argues strongly for early intervention in $\mathrm{OCD}^{36}$. Since early-onset OCD is associated with $\operatorname{tics}^{37}$, a similar argument could be made for early intervention in tic disorders, especially since effective behavioral treatments without side effects are available. Studies of whether early intervention changes the course of tic disorders are needed.

One of the most interesting possibilities in delivering behavior therapy for tics has come from the development of internetbased platforms, making these approaches available for a large number of patients, even in remote areas. The BIP-TIC platform, developed in Sweden, allows to use either habit reversal training (HRT), exposure response prevention (ERP) or a mixture of both online with a possible intervention of a therapist by phone or email. A first pilot study on 23 patients has shown encouraging results in a rater-blind parallel group trial (including a 12 month follow up $)^{38}$. A large $(n=+200)$ UK-based study of ERP using this platform, called ORBIT, will commence shortly ${ }^{39}$.

Another way to increase the number of patients to be reached by CBT is group therapy. A Danish study, using a combined HRT/ERP approach has demonstrated that it is equally effective in a group as in an individual setting with 27 patients per treatment $\mathrm{arm}^{40}$. This represents a promising and interesting way forward in CBT for tics.

Medication. The American Academy of Neurology (AAN) practice guidelines for $\mathrm{TS}^{41,42}$ are one of the most important publications in our field for 2019. A detailed analysis goes way beyond the scope of this review but it might be worth noting that the only "high confidence in the evidence" rating was awarded to Comprehensive Behavioral Intervention for Tics (CBIT) and not pharmacological or surgical therapies for tics. This represents a true paradigm shift in the field. Similar conclusions were drawn in another review of evidence-based treatments for TS and $\mathrm{CTD}^{32}$.

In recent years, cannabis and cannabis-derived products are being considered for the treatment of tics - and a variety of 
other movement disorders. Milosev et al..$^{43}$ present results from a retrospective data analysis and an online survey on the use of cannabis-based medicine for tics and comorbidities in TS. Patients ( $\mathrm{n}=98$ and 40) expressed a preference for medical cannabis (rich in THC) over dronabinol and nabiximols. However, results from large randomized trials are still awaited and will help guide therapeutic decisions. These will also depend, obviously, on the availability of different cannabis-based medications across countries.

Neurosurgery. Blocking tics by behavior therapy or botulinum toxin has been hypothesized to interrupt the sensory-motor feedforward loop likely operating in TS, i.e. premonitory sensations triggering tics which then re-inforce premonitory sensations. Kimura et $a l^{44}$ report on four patients who had undergone thalamic DBS for severe TS. In two, DBS could be completely withdrawn four and seven years after surgery, respectively, without re-increase in tics. This is intriguing and confirms unpublished reports from other centers, including our own (Paris). The authors raise the question of whether some of the tics observed pre-op were functional tics. Alternatively, perhaps some patients with severe tics may need treatment only for several years during development, when tics may have been most severe without treatment. On the topic of functional tics, which are occasionally seen by movement disorder specialists, Ganos et al. ${ }^{45}$ have published a landmark review which should be compulsory reading in the field.

In a 48 month follow-up of a multicentre trial comprising 16 severe TS patients treated with DBS of the anterior pallidum, it was found that $75 \%$ of subjects were treatment responders, that YGTSS (-40\%) and global functioning scores decreased significantly, and that self-injurious behaviors ceased in all affected $(n=7)$ patients ${ }^{46}$. Also, no persistent psychiatric or neurological side effects were noted. However, DBS did not lead to overall decrease in medication. Predictors of long-term outcome for DBS in TS are still needed and larger, perhaps international studies will be able to fill that gap. One step towards that was signalled by a report of initial results from an international TS-DBS registry relating DBS active contact location to outcomes ${ }^{47}$.

Other treatments. Regarding unusual treatment methods for tics, Murakami et al. ${ }^{48}$ describe the use of oral splints in 22 patients with TS. Tic decrease was noted in the vast majority of cases and occurred almost instantaneously. The authors suggest a placebo effect and/or a sensory trick as mechanism of action. The major question here remains how and if such an intervention can work long term and without impairing daily functioning, especially speech.

A pilot study evaluated the efficacy of a resource activation program as an alternative intervention for children and adolescents $(n=24)$ with tic disorders ${ }^{49}$. Their preliminary results suggest that after 16 treatment sessions, tics were significantly diminished using the YGTSS and other tic-related measures. Larger cohorts and longer follow-up will hopefully establish whether this approach might become an alternative or adjunct to established CBT approaches for treating tics such as HRT and ERP.

\section{Conclusions}

They are the same as last year (and likely for a while to come) but worth reiterating, and consist of several simple but important questions: Why do tics tend to start at ages 5-10? Why are they more common in boys? Why do they tend to improve during sleep? Why do tics usually improve in early adulthood? How accurately can we predict outcome for an individual patient? Which patients need which treatments? Is secondary prevention possible? Hopefully future studies will address these and other important issues.

\section{Data availability}

No data are associated with this article.
1. Müller-Vahl KR, Sambrani T, Jakubovski E: Tic disorders revisited: introduction of the term tic spectrum disorders. Eur Child Adolesc Psychiatry. 2019; 28(8): $1129-1135$.

PubMed Abstract | Publisher Full Text | Free Full Text

2. Martino D, Hedderly T: Tics and stereotypies: A comparative clinical review. Parkinsonism Relat Disord. 2019; 59: 117-124.

PubMed Abstract | Publisher Full Text

3. Mainka T, Balint $B$, Gövert $F$, et al.: The spectrum of involuntary vocalizations in humans: A video atlas. Mov Disord. 2019; 34(12): 1774-91. PubMed Abstract | Publisher Full Text

4. Levine JLS, Szejko N, Bloch MH: Meta-analysis: Adulthood prevalence of Tourette syndrome. Prog Neuropsychopharmacol Biol Psychiatry. 2019; 95: 109675.

PubMed Abstract | Publisher Full Text

5. Kim S, Greene DJ, Robichaux-Viehoever A, et al:: Tic suppression in children with recent-onset tics predicts 1-year tic outcome. J Child Neurol. 2019; 34(12): 757-64.

PubMed Abstract | Publisher Full Text | Free Full Text

6. Rae CL, Critchley HD, Seth AK: A Bayesian Account of the Sensory-Motor Interactions Underlying Symptoms of Tourette Syndrome. Front Psychiatry. 2019; 10: 29.

PubMed Abstract | Publisher Full Text | Free Full Text
7. Brander G, Isomura K, Chang Z, et al.: Association of Tourette syndrome and Chronic Tic Disorder with metabolic and cardiovascular disorders. JAMA Neurol. 2019; 76(4): 454-461.

PubMed Abstract | Publisher Full Text | Free Full Text

8. Depienne C, Ciura S, Trouillard O, et al.: Association of Rare Genetic Variants in Opioid Receptors with Tourette Syndrome. Tremor Other Hyperkinet $\operatorname{Mov}(N$ Y). 2019; 9.

PubMed Abstract | Publisher Full Text | Free Full Text

9. Liu S, Tian M, He F, et al.: Mutations in ASH1L confer susceptibility to Tourette syndrome. Mol Psychiatry. 2019; 25(2): 476-490. PubMed Abstract | Publisher Full Text

10. Cappi C, Oliphant ME, Péter Z, et al.: De Novo Damaging DNA Coding Mutations Are Associated With Obsessive-Compulsive Disorder and Overlap With Tourette's Disorder and Autism. Biol Psychiatry. 2019; 87(12): 1035-1044.

PubMed Abstract | Publisher Full Text | Free Full Text

11. Katayama $Y$, Nishiyama $M$, Shoji $H$, et al.: CHD8 haploinsufficiency results in autistic-like phenotypes in mice. Nature. 2016; 537(7622): 675-9. PubMed Abstract | Publisher Full Text

12. Cesta CE, Öberg AS, Ibrahimson A, et al.: Maternal polycystic ovary syndrome and risk of neuropsychiatric disorders in offspring: prenatal androgen exposure or genetic confounding? Psychol Med. 2019; 50(4): 616-624. PubMed Abstract | Publisher Full Text | Free Full Text 
13. Brander G, Kuja-Halkola R, Rosenqvist MA, et al:: A population-based family clustering study of tic-related obsessive-compulsive disorder. $\mathrm{Mol}$ Psychiatry. 2019.

PubMed Abstract | Publisher Full Text

14. Baglioni V, Coutinho E, Menassa DA, et al.: Antibodies to neuronal surface proteins in Tourette Syndrome: Lack of evidence in a European paediatric cohort. Brain Behav Immun. 2019; 81: 665-9.

PubMed Abstract | Publisher Full Text

15. Baumgaertel C, Skripuletz T, Kronenberg J, et al.: Immunity in Gilles de la Tourette-Syndrome: Results From a Cerebrospinal Fluid Study. Front Neurol. 2019; 10: 732

PubMed Abstract | Publisher Full Text | Free Full Text

16. Gilbert DL: Inflammation in Tic Disorders and Obsessive-Compulsive Disorder: Are PANS and PANDAS a Path Forward? J Child Neurol. 2019; 34(10): 598-611.

PubMed Abstract | Publisher Full Text

17. Chen SF, Su YC, Wang LY, et al.: Tourette's syndrome is associated with an increased risk of traumatic brain injury: A nationwide population-based cohort study. Parkinsonism Relat Disord. 2019; 63: 88-93. PubMed Abstract | Publisher Full Text

18. Augustine F, Singer HS: Merging the Pathophysiology and Pharmacotherapy of Tics. Tremor Other Hyperkinet Mov (N Y) 2019; 8: 595. PubMed Abstract | Publisher Full Text | Free Full Text

19. Singer HS, Augustine F: Controversies Surrounding the Pathophysiology of Tics. J Child Neurol. 2019; 34(13): 851-862. PubMed Abstract | Publisher Full Text

20. Loo SK, Miyakoshi M, Tung K, et al:: Neural activation and connectivity during cued eye blinks in Chronic Tic Disorders. Neuroimage Clin. 2019; 24 101956.

PubMed Abstract | Publisher Full Text | Free Full Text

21. Niccolai $\mathrm{V}$, Korczok S, Finis J, et al.: A peek into premonitory urges in Tourette syndrome: Temporal evolution of neurophysiological oscillatory signatures. Parkinsonism Relat Disord. 2019; 65: 153-8. PubMed Abstract | Publisher Full Text

22. Zapparoli L, Macerollo A, Joyce EM, et al.: Voluntary tic suppression and the normalization of motor cortical beta power in Gilles de la Tourette syndrome: an EEG study. Eur J Neurosci. 2019; 50(12): 3944-57. PubMed Abstract | Publisher Full Text

23. Zhu GY, Geng XY, Zhang RL, et al.: Deep brain stimulation modulates pallida and subthalamic neural oscillations in Tourette's syndrome. Brain Behav. 2019; 9(12): e01450.

PubMed Abstract | Publisher Full Text | Free Full Text

24. Vissani M, Cordella R, Micera S, et al:: Spatio-temporal structure of single neuron subthalamic activity identifies DBS target for anesthetized Tourette syndrome patients. J Neural Eng. 2019; 16(6): 066011. PubMed Abstract | Publisher Full Text

25. Ramkiran $\mathrm{S}$, Heidemeyer $\mathrm{L}$, Gaebler $\mathrm{A}$, et al.: Alterations in basal gangliacerebello-thalamo-cortical connectivity and whole brain functional network topology in Tourette's syndrome. Neuroimage Clin. 2019; 24: 101998. PubMed Abstract | Publisher Full Text | Free Full Text

26. Sigurdsson HP, Jackson SR, Jolley L, et al.: Alterations in cerebellar grey matter structure and covariance networks in young people with Tourette syndrome. Cortex. 2020; 126: 1-15. PubMed Abstract | Publisher Full Text

27. Jackson SR, Loayza J, Crighton M, et al.: The role of the insula in the generation of motor tics and the experience of the premonitory urge-to-tic in Tourette syndrome. Cortex. 2020; 126: 119-33.

PubMed Abstract | Publisher Full Text

28. Nielsen AN, Gratton C, Church JA, et al.: Atypical Functional Connectivity in Tourette Syndrome Differs Between Children and Adults. Biol Psychiatry. 2020; 87(2): 164-73.

PubMed Abstract | Publisher Full Text | Free Full Text

29. O'Neill J, Piacentini JC, Peterson BS: Cingulate role in Tourette syndrome. Handb Clin Neurol. 2019; 166: 165-221. PubMed Abstract | Publisher Full Text

30. Müller-Vahl KR, Szejko N, Wilke F, et al: Serotonin transporter binding is increased in Tourette syndrome with Obsessive Compulsive Disorder. $\mathrm{SC}$ Rep. 2019; 9(1): 972.

PubMed Abstract | Publisher Full Text | Free Full Text

31. Martino D, Hartmann A, Pelosin E, et al.: Motor Timing in Tourette Syndrome: The Effect of Movement Lateralization and Bimanual Coordination. Front Neurol. 2019; 10: 385.

PubMed Abstract | Publisher Full Text | Free Full Text
32. Essoe JK, Grados MA, Singer HS, et al.: Evidence-based treatment of Tourette's disorder and chronic tic disorders. Expert Rev Neurother. 2019; 19(11): 1103-1115. PubMed Abstract | Publisher Full Text

33. Maigaard K, Nejad AB, Andersen KW, et al.: A superior ability to suppress fast inappropriate responses in children with Tourette syndrome is further improved by prospect of reward. Neuropsychologia. 2019; 131: 342-52. PubMed Abstract | Publisher Full Text

34. Conelea CA, Wellen B, Woods DW, et al.: Patterns and Predictors of Tic Suppressibility in Youth With Tic Disorders. Front Psychiatry. 2018; 9: 188 PubMed Abstract | Publisher Full Text | Free Full Text

35. Rozenman M, Piacentini J, O'Neill J, et al.: Improvement in anxiety and depression symptoms following cognitive behavior therapy for pediatric obsessive compulsive disorder. Psychiatry Res. 2019; 276: 115-23. PubMed Abstract | Publisher Full Text | Free Full Text

36. Fineberg NA, Dell'Osso B, Albert U, et al.: Early intervention for obsessive compulsive disorder: An expert consensus statement. Eur Neuropsychopharmacol. 2019; 29(4): 549-565.

PubMed Abstract | Publisher Full Text

37. Taylor S: Early versus late onset obsessive-compulsive disorder: evidence for distinct subtypes. Clin Psychol Rev. 2011; 31(7): 1083-100. PubMed Abstract | Publisher Full Text

38. Andrén $\mathrm{P}$, Aspvall $\mathrm{K}, \mathrm{Cruz} \mathrm{L}$, et al.: Therapist-guided and parent-guided internet-delivered behaviour therapy for paediatric Tourette's disorder: a pilot randomised controlled trial with long-term follow-up. BMJ Open. 2019; 9(2): e024685

PubMed Abstract | Publisher Full Text | Free Full Text

39. Hall $C L$, Davies $E B$, Andrén $P$, et al.: Investigating a therapist-guided, parentassisted remote digital behavioural intervention for tics in children and adolescents-'Online Remote Behavioural Intervention for Tics' (ORBIT) trial: protocol of an internal pilot study and single-blind randomised controlled trial. BMJ Open. 2019; 9(1): e027583. PubMed Abstract | Publisher Full Text | Free Full Text

40. Nissen JB, Kaergaard M, Laursen L, et al.: Combined habit reversal training and exposure response prevention in a group setting compared to individual training: a randomized controlled clinical trial. Eur Child Adolesc Psychiatry. 2019; 28(1): 57-68.

PubMed Abstract | Publisher Full Text | Free Full Text

41. Pringsheim T, Okun MS, Müller-Vahl K, et al.: Practice guideline recommendations summary: Treatment of tics in people with Tourette syndrome and chronic tic disorders. Neurology. 2019; 92(19): 896-906. PubMed Abstract | Publisher Full Text | Free Full Text

42. Pringsheim T, Holler-Managan $Y$, Okun MS, et al.: Comprehensive systematic review summary: Treatment of tics in people with Tourette syndrome and chronic tic disorders. Neurology. 2019; 92(19): 907-15.

PubMed Abstract | Publisher Full Text | Free Full Text

43. Milosev LM, Psathakis N, Szejko N, et al.: Treatment of Gilles de la Tourette Syndrome with Cannabis-Based Medicine: Results from a Retrospective Analysis and Online Survey. Cannabis Cannabinoid Res. 2019; 4(4): 265-74. PubMed Abstract | Publisher Full Text | Free Full Text

44. Kimura Y, Ikegaya N, Iijima K, et al.: Withdrawal of deep brain stimulation in patients with gilles de la tourette syndrome. Mov Disord. 2019; 34(12): 1925-6.

PubMed Abstract | Publisher Full Text

45. Ganos C, Martino D, Espay AJ, et al:: Tics and functional tic-like movements: Can we tell them apart? Neurology. 2019; 93(17): 750-8. PubMed Abstract | Publisher Full Text

46. Welter ML, Houeto JL, Worbe $Y$, et al.: Long-term effects of anterior pallidal deep brain stimulation for tourette's syndrome. Mov Disord. 2019; 34(4): 586-8.

PubMed Abstract | Publisher Full Text

47. Johnson KA, Fletcher PT, Servello D, et al.: Image-based analysis and longterm clinical outcomes of deep brain stimulation for Tourette syndrome: a multisite study. J Neurol Neurosurg Psychiatry. 2019; 90(10): 1078-90. PubMed Abstract | Publisher Full Text | Free Full Text

48. Murakami J, Tachibana Y, Akiyama S, et al.: Oral splint ameliorates tic symptoms in patients with tourette syndrome. Mov Disord. 2019; 34(10): $1577-8$.

PubMed Abstract | Publisher Full Text | Free Full Text

49. Viefhaus $P$, Feldhausen $M$, Görtz-Dorten $A$, et al.: A new treatment for children with chronic tic disorders - Resource activation. Psychiatry Res. 2019; 273: 662-71.

PubMed Abstract | Publisher Full Text 


\section{Open Peer Review}

\section{Current Peer Review Status:}

\section{Version 2}

Reviewer Report 13 January 2021

https://doi.org/10.5256/f1000research.31048.r75789

(C) 2021 Hedderly T. This is an open access peer review report distributed under the terms of the Creative Commons Attribution License, which permits unrestricted use, distribution, and reproduction in any medium, provided the original work is properly cited.

\section{Tammy Hedderly}

1 Tic and Neurodevelopmental Movements Service (TANDeM), Evelina Children's Hospital, London, UK

2 GSTT/KCL, London, UK

The authors are now experts in providing a detailed and helpful summary of the research in Tourette. As a practitioner in the field I find these annual updates extremely helpful and know many that share this view. The paper is well referenced and although the summary of each paper is brief it allows for easy access to the relevant papers. Next year I would like to see some of the papers on functional tics included and of course we may expect to see a discussion around the impact of COVID in these challenging times. I strongly support the indexing of this helpful review paper and thank the authors for their helpful summary of this years papers.

Is the topic of the review discussed comprehensively in the context of the current literature?

Yes

Are all factual statements correct and adequately supported by citations? Yes

Is the review written in accessible language?

Yes

Are the conclusions drawn appropriate in the context of the current research literature? Yes

Competing Interests: No competing interests were disclosed.

Reviewer Expertise: Lead of Tourette Services-clinical

I confirm that I have read this submission and believe that I have an appropriate level of 
expertise to confirm that it is of an acceptable scientific standard.

Reviewer Report 04 December 2020

https://doi.org/10.5256/f1000research.31048.r75777

(c) 2020 Szejko N. This is an open access peer review report distributed under the terms of the Creative Commons Attribution License, which permits unrestricted use, distribution, and reproduction in any medium, provided the original work is properly cited.

\section{Natalia Szejko}

1 Department of Neurology, Medical University of Warsaw, Warsaw, Poland

2 Department of Neurology, Yale School of Medicine, Yale University, New Haven, CT, USA

Thank you so much for addressing these small issues, now the article reads well, I do not have any further comments.

Is the topic of the review discussed comprehensively in the context of the current literature?

Yes

Are all factual statements correct and adequately supported by citations?

Yes

Is the review written in accessible language?

Yes

Are the conclusions drawn appropriate in the context of the current research literature? Yes

Competing Interests: No competing interests were disclosed.

Reviewer Expertise: Tourette syndrome, movement disorders, neuropsychiatry, cannabis based medicine in neurology and psychiatry, functional movement disorders

I confirm that I have read this submission and believe that I have an appropriate level of expertise to confirm that it is of an acceptable scientific standard.

\section{Version 1}

Reviewer Report 23 November 2020

https://doi.org/10.5256/f1000research.30253.r74624 
(c) 2020 Szejko N. This is an open access peer review report distributed under the terms of the Creative Commons Attribution License, which permits unrestricted use, distribution, and reproduction in any medium, provided the original work is properly cited.

\section{Natalia Szejko}

1 Department of Neurology, Medical University of Warsaw, Warsaw, Poland

2 Department of Neurology, Yale School of Medicine, Yale University, New Haven, CT, USA

3 Department of Neurology, Medical University of Warsaw, Warsaw, Poland

4 Department of Neurology, Yale School of Medicine, Yale University, New Haven, CT, USA

This article offers greatly appreciated year summary of the most important articles about TS published in 2019. The authors gave a detailed overview of studies dedicated to tics and divided their findings into thematic sections to give these results more organization. I also appreciate the conclusions presented as questions raised by the researchers the previous year.

However, I would recommend to change a language for more formal and also correct several "typos". For example, in the results section, the authors of the study are not mentioned in this sentence: "1 present a stimulating argument based on data that demonstrate a severity continuum between chronic tics and TS using a database regrouping 1018 subjects"; the sentence is merely starting with the reference, instead. The same happens at several other occasions. In some points, I also missed more detailed conclusions, for example regarding the TBI risk in TS, where it is only stated that "These findings have important therapeutic implications". I would also introduce the separated section regarding the reviews of some particular topics, as in the "Pathophysiology" section where the study by Singer and Augustine should be described with more details and proceeded by the heading "Reviews".

\section{Is the topic of the review discussed comprehensively in the context of the current literature? \\ Yes}

\section{Are all factual statements correct and adequately supported by citations?}

Yes

Is the review written in accessible language?

Partly

Are the conclusions drawn appropriate in the context of the current research literature? Yes

Competing Interests: No competing interests were disclosed.

Reviewer Expertise: Tourette syndrome, movement disorders, neuropsychiatry, cannabis based medicine in neurology and psychiatry, functional movement disorders

I confirm that I have read this submission and believe that I have an appropriate level of 


\section{expertise to confirm that it is of an acceptable scientific standard, however I have} significant reservations, as outlined above.

\section{Author Response 23 Nov 2020}

\section{Andreas Hartmann}

We thank the reviewer for their appreciation of our work.

Regarding formatting (i.e., changing author names by numbers), this was done by F1000 and we will check with them whether it can be changed. The idea, obviously, was not to be informal but simply to stick to the rules. We have also rechecked for typos.

As requested, we have expanded on the paper regarding TBI and TS.

As to the tow reviews by Singer, they are exhaustive and do not point out to single results, so it is impossible to give a major result or take home message: we simply wished to bring them to the attention of readers wishing to dwell into the broader subject of TS pathophysiology.

Competing Interests: No competing interests were disclosed.

The benefits of publishing with F1000Research:

- Your article is published within days, with no editorial bias

- You can publish traditional articles, null/negative results, case reports, data notes and more

- The peer review process is transparent and collaborative

- Your article is indexed in PubMed after passing peer review

- Dedicated customer support at every stage

For pre-submission enquiries, contact research@f1000.com 